\title{
A New Measure for Individual Thermal Comfort
}

Seçkin Ar1 ${ }^{1}$, DH. Ezzat Khalifa², (DPeter Wilcoxen ${ }^{3}$, (DCan Isik ${ }^{4}$, (D) John F. Dannenhoffer III ${ }^{5}$

${ }^{1}$ Sakarya University; ari@sakarya.edu.tr; 0000-0001-7556-8205; +90-264-295-6175

${ }^{2}$ Syracuse University; hekhalif@syr.edu; 0000-0002-3719-2136

3Syracuse University; wilcoxen@maxwell.syr.edu; 0000-0001-8614-3982

${ }^{4}$ Syracuse University; cisik@syr.edu; 0000-0003-2894-4540

${ }^{5}$ Syracuse University; jfdannen@syr.edu; 0000-0002-2244-2921

Received 18 December 2019; Revised 19 March 2020; Accepted 27 March 2020; Published online 30 April 2020

\begin{abstract}
This paper introduces a new measure for individual thermal comfort, inspired by the current standards for population thermal comfort, and a statistical model allowing us to imitate individuals' thermal comfort preferences. Our approach is based on the observation that an individual has a temperature range around his or her desired temperature point in which he or she is comfortable with the surrounding thermal environment. The crucial parameters of our statistical model, which represents the thermal characteristic of individuals of building occupants, have been assumed to be normally distributed random variables so that the thermal comfort preferences of different individuals can be generated for the further simulation purposes. When aggregated to a population's general thermal comfort parameters, the variables of these distributions have been adjusted in such a way as to bring very close consistency with the current standards, which define the criteria for acceptable thermal conditions of human occupancy in a built environment.
\end{abstract}

Keywords: Modeling, Thermal Comfort, Indoor Environment, PMV, PPD

\section{Bireysel Isısal Memnuniyet için Yeni Bir Ölçü}

\section{Öz}

Bu çalışma topluluk için ısısal memnuniyet standardından esinlenerek bireysel ısısal memnuniyet için yeni bir ölçü ve kişilerin ısısal konfor tercihlerini taklit etmemizi sağlayan istatistiksel bir model sunmaktadır. Yaklaşımımız, bir bireyin arzu ettiği sıcaklık değeri civarında kendilerini çevreleyen ısısal ortamdan memnun oldukları bir sıcaklık aralığına sahip oldukları gözlemine dayanır. Bina sakinlerinin bireysel ısısal tercihlerini temsil eden istatistiksel modelimizin önemli parametrelerinin normal dağılıma sahip rastgele değişkenler olduğu varsayılmıştır, böylece daha sonra gerçekleştirilmek istenebilecek benzetimler için farklı bireylerin 1sısal konfor tercihleri üretilebilir hale gelecektir. Bu dağılımın değişkenleri, topluluğa ait ısısal konfor parametlerini elde etmek için birleştirildiğinde bir bina içerisindeki kabul edilebilir ısısal koşulları belirleyen standartlara çok yakın tutarlılık sağlayacak şekilde ayarlanmıştır.

Anahtar Kelimeler: Modelleme, Isısal Memnuniyet, Kapalı Mekan, PMV, PPD

\section{Introduction}

Buildings utilize one-third of energy consumption in the US, and nearly $40-60 \%$ of the overall energy consumption in buildings is comprised of typical heating, ventilating, and air conditioning systems for maintaining thermal comfort [1]. Advancing technology of society leads to most people (more than 95\%) in industrially developed countries spending more than $90 \%$ of their time in a man-made, artificially climatic environments (buildings, vehicles, etc.) [2], [3]. Because of this fact, the interest in environmental systems has been increased for decades. 
Researchers have presented many studies about thermal comfort indices in the literature. We will give a brief introduction of the relevant studies in this section. Then, the standards for thermal comfort of human occupancy will be explained.

The first study regarding thermal comfort was presented by Houghton and Yaglou in 1923 [4]. In order to measure thermal comfort in an environment, they introduced the first temperature scale in terms of dry bulb temperature and humidity level. This scale was named the original American Society of Heating and Ventilating Engineers (ASHVE) Effective Temperature (ET) comfort chart and was widely used for almost 50 years all over the world. After the 1930s, there has been a significant increase in the number of studies on making a realistic prediction of comfort and body and skin temperatures. Realistic models of energy exchange between the skin surface and the ambient environment have been the main factor of thermal comfort indices [5], [6]. Winslow et al. [5] described a skin wettedness index of thermal discomfort in terms of different parts of body surface. Two concentric cylinders, which are a core cylinder and a thin skin cylinder surrounding it, were used to imitate the human body. Their index estimates thermal discomfort using skin wettedness and air temperature. Yaglou [6] developed a different scale reducing the effect of humidity towards lower temperatures. In 1971, Gagge et al. [7] showed the importance of dry bulb temperature and humidity in thermal comfort of human occupancy. In their study, they improved the original ASHVE ET comfort chart derived by Houghton and Yaglou in [4]. Their new Effective Temperature (ET*) and standard effective temperature (SET*) is based on the heat production of the human body and sweating. SET ${ }^{*}$ stands for an effective temperature relative to a standard person in a standard indoor environment. They used the same cylindrical model of the human body as the one Winslow used in his study [5].

Fanger presented a more realistic approach to thermal comfort in 1967 [8]. Unlike Gagge et al.'s ET* [7], which specifically takes into account only ambient temperature and humidity, Fanger's index accounts for the following six crucial variables: metabolic rate, clothing, air temperature, radiant temperature, air velocity, and relative humidity. Fanger's overall goal is to calculate thermal comfort for a large group of people with regard to their surrounding environmental conditions. In his study, Fanger [8] established a basic comfort equation in terms of air temperature, humidity, mean radiant temperature, air velocity, activity level, and the insulation value of clothing. He assumed that both the mean skin temperature and the sweat secretion related to internal body temperature are primary parameters influencing thermal comfort.

Fanger [8] presented his comfort equation based on the heat balance of the human body. First, he developed a heat balance equation for a large group of people under the assumption that the heat generation of the human body is equal to its heat loss when it is exposed to a steady state thermal environment in his study. His comfort equation is used to calculate all the combinations of environmental variables such as air temperature or air humidity, to achieve optimal thermal comfort for a population with a given activity level and clothing value. This comfort equation, however, does not point out the degree of discomfort of a population. Therefore, it is not appropriate for the prediction of thermal comfort for a whole population at a certain environmental condition.

Starting from his comfort equation, Fanger introduced a new thermal sensation index (Predicted Mean Vote - PMV ) in 1972 as well [2], which makes it possible to predict the thermal satisfaction of a population under any indoor environmental conditions. In order to develop a thermal sensation index, he used the 7-point psycho-physical ASHRAE scale changing from -3 , cold, to +3 , hot. The meaning of the scale is given in Table 1 .

Table 17 - point PMV scale

\begin{tabular}{|c|l|}
\hline Vote & \multicolumn{1}{|c|}{ Meaning } \\
\hline-3 & Cold \\
\hline-2 & Cool \\
\hline-1 & Slightly cool \\
\hline 0 & Neutral \\
\hline+1 & Slightly warm \\
\hline+2 & Warm \\
\hline+3 & Hot \\
\hline
\end{tabular}


By establishing a relationship between this 7-point ASHRAE scale and his comfort equation, he developed his PMV equation based on the experimentally collected data of McNall et al. [9] and Nevins et al. [10]. In these experiments, 1396 subjects submitted their votes with regard to their surrounding thermal environmental conditions in a place where the clothing, activity, and environmental parameters were strictly controlled. This PMV equation estimates the thermal sensation of a large group of people with any combination of personal and environmental variables.

In addition to this PMV equation, Fanger also showed how to correlate that equation with the discomfort level of a large group of people by giving a relationship between the percentage of dissatisfied people and their mean votes. He presented a table of Predicted Percentage of Dissatisfied (PPD) people for different PMV values by using the experimentally acquired data of Fanger [2], Nevins et al. [10], and Rohles [11]. In these experiments, 1296 subjects were allowed to vote with regard to their thermal satisfaction with the surrounding environment based on the seven - point scale. Using Gagge et. al' s definition of thermal satisfaction in [12], Fanger classified the people voting -3 ( cold ), -2 ( cool ), +2 ( warm ), and +3 ( hot ) as measure of their dissatisfaction, and the people voting -1 ( slightly cool ), 0 ( neutral ), and +1 ( slightly warm ) as measure of their satisfaction with their surrounding thermal environment. This two-state classification is called a binary approach in this study.

Both PMV and ET* have been developed under the assumption of the steady-state heat transfer between a clothed human body and the environment. In order to take into account humidity effects in detail, Gagge et al. modified Fanger's Predicted Mean Vote equation by introducing a new thermal sensation index, called SPI in [13]. They proposed the new SPI for any humid or dry environment by substituting operative temperature in Fanger's PMV equation with SET*. However, the current standards still utilize Fanger's PMV and PPD equations to define thermal comfort requirements of occupants in built environments as a standard.

The modified PMV equation and a fitted curve to Fanger's PPD data (equation 1), which is illustrated in Figure 1, have been widely accepted by the American Society of Heating, Refrigerating, and AirConditioning Engineers ( ASHRAE ) and the International Organization for Standardization ( ISO ) as a standard for the thermal satisfaction of human occupancy in a built environment. This function, which is given in equation 1, estimates the dissatisfaction level of a population for a given PMV value.

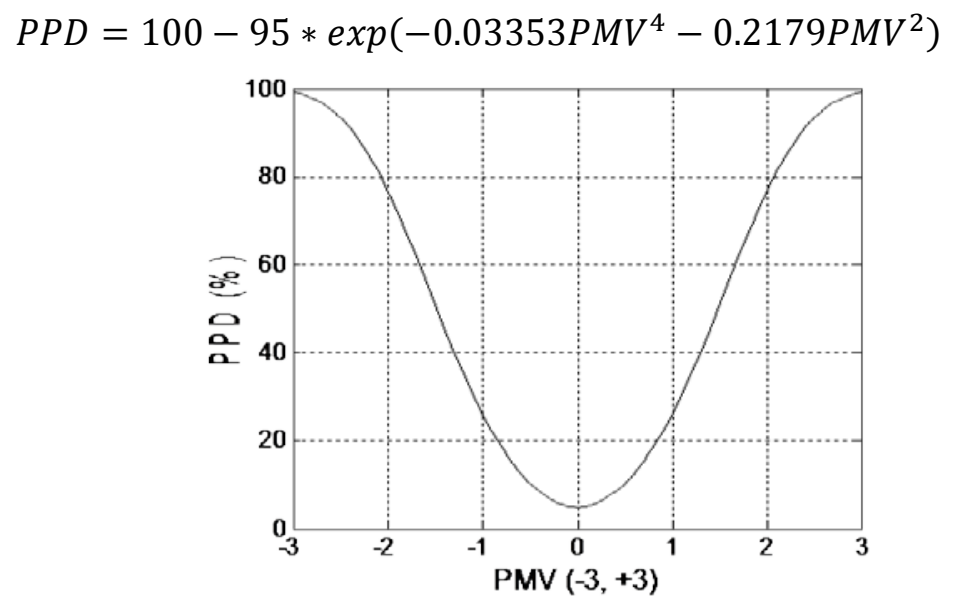

Figure 1 Predicted Percentage of Dissatisfied as a function of Predicted Mean Vote

The published standards, such as those of ASHRAE 55 - 2004 [14] and the ISO 7730:2003 [15] adopted Fanger's study with small modifications. These standards specify the criteria for maintaining acceptable thermal environmental conditions to a majority of the occupants wherever man-made climates are supplied for human occupancy based on a combination of personal factors (thermal resistance of the clothing and activity level) and environmental factors (air temperature, mean radiant temperature, relative air velocity, and relative humidity). If a building's occupants are in the same surrounding environment, then it will be impossible to satisfy everybody with regard to their surrounding thermal environmental conditions at the same time because of the individuals' biological and psychological differences. Therefore, the standards are based on average criteria for population comfort. Buildings and their environmental control systems are designed according to the descriptions in these standards to 
provide an acceptable thermal environment to $80 \%$ of a large group of people. The conventional comfort perception in ASHRAE Standard 55 - 2004 specifies a comfort zone of temperatures to be applied uniformly through a space that is regulated by a small number of thermostats.

The outline required environmental conditions for human thermal comfort have been defined above. In the next section, we will introduce our approach to thermal comfort which allows us to generate thermal comfort preferences of occupants in a building.

\section{Methods}

In this study, our aim is to model thermal comfort characteristic of individuals and to validate this model with the standards when aggregated to population's thermal comfort. In this section, we will present our approach to individual thermal comfort.

\subsection{Individual Thermal Comfort}

Fanger's classification of dissatisfied and satisfied people [2] and Rohles's survey data [16] confirmed that a person is in comfortable thermal environment at a range of temperatures rather than at a single temperature point. In this study, we did not have the opportunity of doing thermal comfort experiments of indoor environmental control systems with human subjects. Two random distributions have been developed for the future simulated experiments to generate preferred temperature, $T_{p}$ and temperature tolerance (comfort range) for departure from $T_{p}, \Delta$ for each individual.

The variables $T_{p}$ and $\Delta$ must ensure the conditions given as follows:

1. An individual vote should be zero (neutral) when the surrounding temperature $T_{a}$ equals to the person's desired temperature $T_{p}$.

2. The value of each individual vote should be +1.5 or -1.5 when the deviation between the ambient temperature $T_{a}$ and the desired temperature $T_{p}$ is $\Delta$, corresponding to Fanger's classification of dissatisfied and satisfied people based on the discrete seven-point ASHRAE thermal sensation scale.

3. Each individual predicted vote $(P V)$ value should reach the minimum $(-3)$ or the maximum $(+3)$ value of thermal sensation scale depending on $T_{a}$ after the deviation is $2 \Delta$ from $T_{p}$.

4. The mean value of individual $P V$ s should match up Fanger's $P M V$ equation at a given ambient temperature.

We assumed that an individual vote is a first order function of the ambient temperature $T_{a}$ when the activity level, clothing value, and the environmental parameters are constant. When the individual is in a steady indoor environment at temperature $T_{a}$, his predicted vote (PV) is assumed to be determined according to equation 2, which is illustrated in Figure 2.

$$
P V\left(T_{a}\right)=\left\{\begin{array}{rc}
+3, & \left(T_{a}-T_{p}\right)>2 \Delta \\
-3, & \left(T_{a}-T_{p}\right)<2 \Delta \\
\frac{3}{2 \Delta}\left(T_{a}-T_{p}\right), & \text { otherwise }
\end{array}\right.
$$




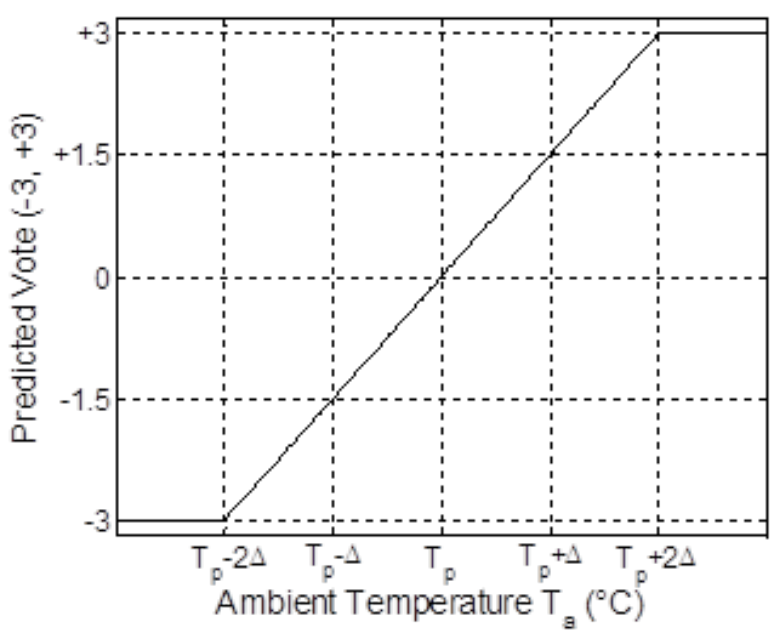

Figure 2 Predicted individual vote

We have chosen that linear function because of its simplicity, although any smooth and continuous function satisfying the conditions mentioned above could be used.

A new measure - the Degree of Individual Dissatisfaction ( DID ) - is also introduced to define individual dissatisfaction as a fuzzy concept over a continuous scale from 0 (totally satisfied) to 1 (totally dissatisfied) rather than a binary one, which has been utilized by Fanger in [2]. A binary approach implies an intuitively implausible discontinuity in satisfaction, while our DID measure allows the concept of dissatisfaction to change smooth with the predicted vote, ranging from 0 when the person is completely satisfied to 1 when the person is fully dissatisfied. In order to develop this concept, we will assume that a smooth, symmetric, closed - form function can be found to represent the relationship between DID and individual vote. A hyperbolic tangent function, which is illustrated in figure 3, has been used in this study since it is smooth and easily differentiable. If future experimental studies lead to other functional representations, equation 3 can be modified easily without any conceptual or algorithmic complications.

The DID function should satisfy the following three conditions:

1. The $D I D$ value of an individual should be 0 when $P V$ is zero: The occupant is $100 \%$ satisfied when $T_{a}$ equals $T_{p}$

2. The $D I D$ value of an individual should be 0.5 when $P V$ is +1.5 or -1.5 : The occupant is $50 \%$ satisfied when the difference between $T_{a}$ and $T_{p}$ is $\Delta$.

3. The $D I D$ value of an individual should be 1 when $P V$ is +3 or -3 : The occupant is $100 \%$ dissatisfied when the difference between $T_{a}$ and $T_{p}$ is $2 \Delta$.

$$
\operatorname{DID}(P V)=\frac{1+\tanh (2|P V|-3)}{2}
$$

When equations 2 and 3 are combined to equation 4, a bucket - shaped DID curve demonstrated in figure 3 can be generated for each member of population in a building.

$$
\operatorname{DID}\left(T_{a}\right)=\left\{\begin{array}{rr}
+1, & \left|T_{a}-T_{p}\right|>2 \Delta \\
\frac{1}{2}\left[1+\tanh \left(\frac{3}{\Delta}\left|T_{a}-T_{p}\right|-3\right)\right], & \text { otherwise }
\end{array}\right.
$$




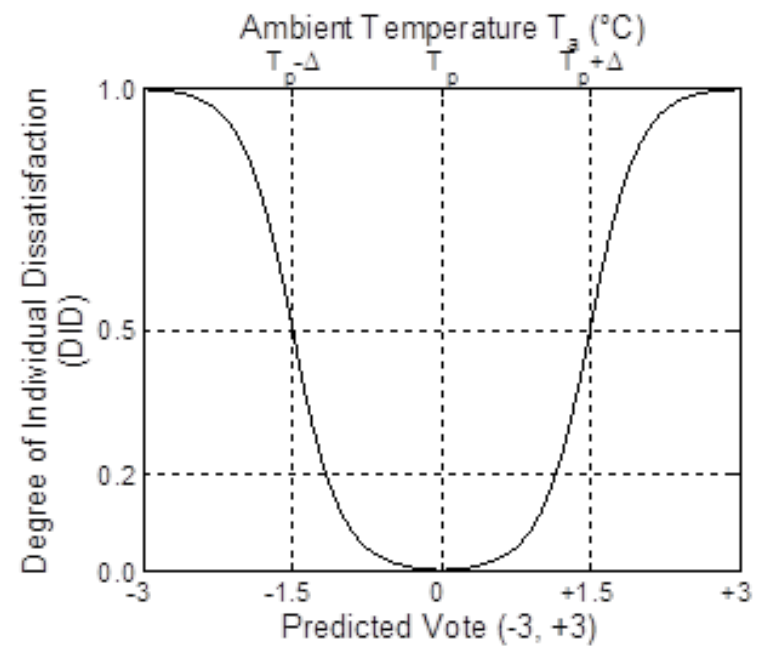

Figure 3 Individual dissatisfaction curve

The curves will be different due to individual preferences about a value of $T_{p}$ and with a width $\Delta$. One consequence may be that there is no single temperature with which everyone is completely satisfied. At this moment, we are capable of generating populations of building occupants having characteristic thermal comfort preferences with the presented model. Figure 4 is an example of a given population of 9 individuals, which are generated with our individual thermal comfort model.

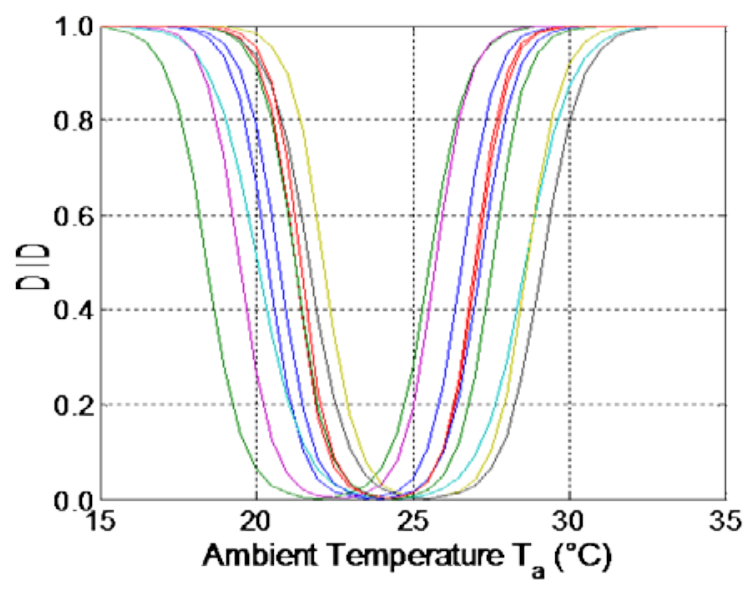

Figure 4 A generated population of 9 individuals

The only way to validate our individual thermal comfort model is to compare it with the thermal comfort standards for a large group of people. Therefore, we will need to calculate the dissatisfaction level of a generated population using the PV lines and DID curves of every individual. The average of the individual PVs and the average DID values of individual occupants at a given ambient temperature $\left(T_{a}\right)$ allows us to calculate PMV and PPD values for the population at that temperature, respectively.

$$
\begin{gathered}
\operatorname{PMV}_{\text {gen }}\left(T_{a}\right)=\frac{1}{N} \sum_{i=1}^{N} P V_{i}\left(T_{a}\right) \\
\operatorname{PPD}_{\text {gen }}\left(T_{a}\right)=\frac{1}{N} \sum_{i=1}^{N} \operatorname{DID}\left(P V_{i}\left(T_{a}\right)\right)
\end{gathered}
$$

\section{Results}

In order to assign values to the parameters of our statistical model, some assumptions have been made for all of the personal and some of the environmental parameters of thermal sensation. Individual occupants are assumed to do basic office activities while wearing business clothing in a steady state 
thermal environment. The ASHRAE standard restricts the air velocity to be not greater than $0.2 \mathrm{~m} / \mathrm{s}$. Therefore, we also assumed that air velocity is $0.1 \mathrm{~m} / \mathrm{s}$, having $50 \%$ relative humidity. In order to adjust the mean values and standard deviations of both distributions of $T_{p}$ and $\Delta$ with the above assumptions, a Monte - Carlo simulation has been run with those parameters. We repeatedly generated a population of 1000 individuals with different distribution parameters in each iteration to find reasonable parameters allowing the overall $\mathrm{PPD}_{\text {gen }}-\mathrm{PMV}_{\text {gen }}$ curve of the generated population to fit the standard PPD - PMV curve in [14].

We found several mean values and standard deviations for $T_{p}$, and $\Delta$ resulting in similar deviations from the standards. Our analysis yielded mean values for $T_{p}$ and $\Delta$ of $24{ }^{\circ} \mathrm{C}$, and $3.2^{\circ} \mathrm{C}$, respectively, and standard deviations for $T_{p}$, and $\Delta$ of $1.2^{\circ} \mathrm{C}$, and $0.5^{\circ} \mathrm{C}$, respectively.

Figure 5 shows the generated PMV to the original PMV equation in the ASHRAE standard as a function of $T_{a}$ when the personal and the other environmental parameters are constant with the root mean squared error of 0.08 . The $P M V_{\text {gen }}$ of a generated population will be neutral when the ambient temperature $T_{a}$ is the mean value of $T_{p}\left(24^{\circ} \mathrm{C}\right)$.

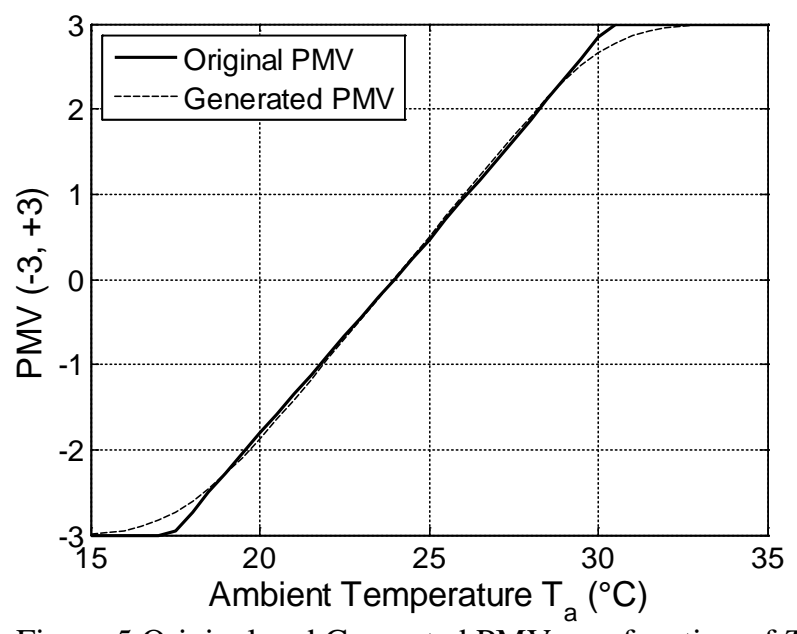

Figure 5 Original and Generated PMV as a function of $T_{a}$

Figure 6 shows the generated PPD-PMV curve to the original PPD-PMV curve in the ASHRAE standard 55 with the root mean squared error of about 0.01 .

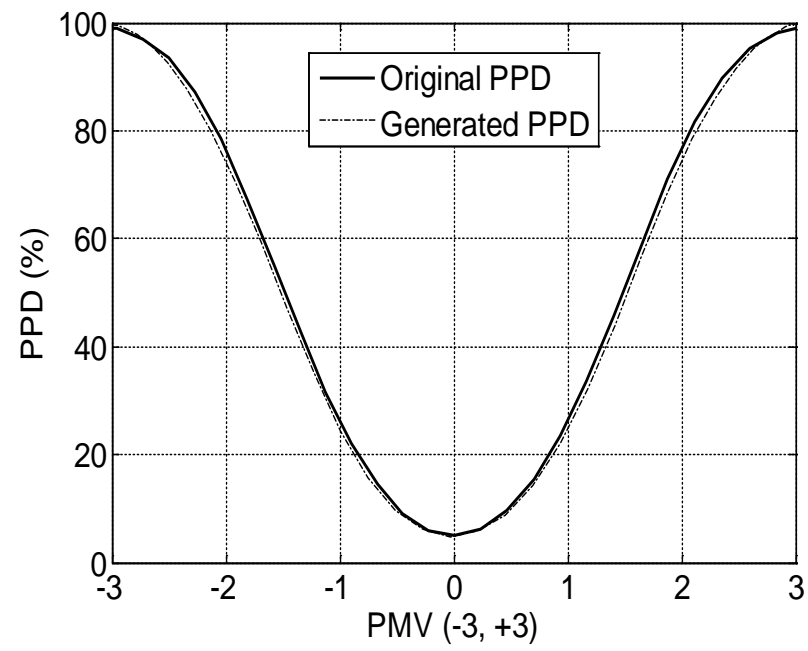

Figure 6 Original and Generated PPD curves

The following is an example of thermal comfort computation for a generated population via our distributions at a given ambient temperature. 


\section{An Example Population}

Our individual thermal comfort model is capable of assigning two different functions to a population of occupants into any building. Figure 7 demonstrates the histograms of desired temperatures and temperature ranges for an example population of 49 occupants, who are simulated with the presented distributions of individual thermal comfort preferences (preferred temperature, $T_{p}$, and comfortable temperature range, $\Delta$ ).
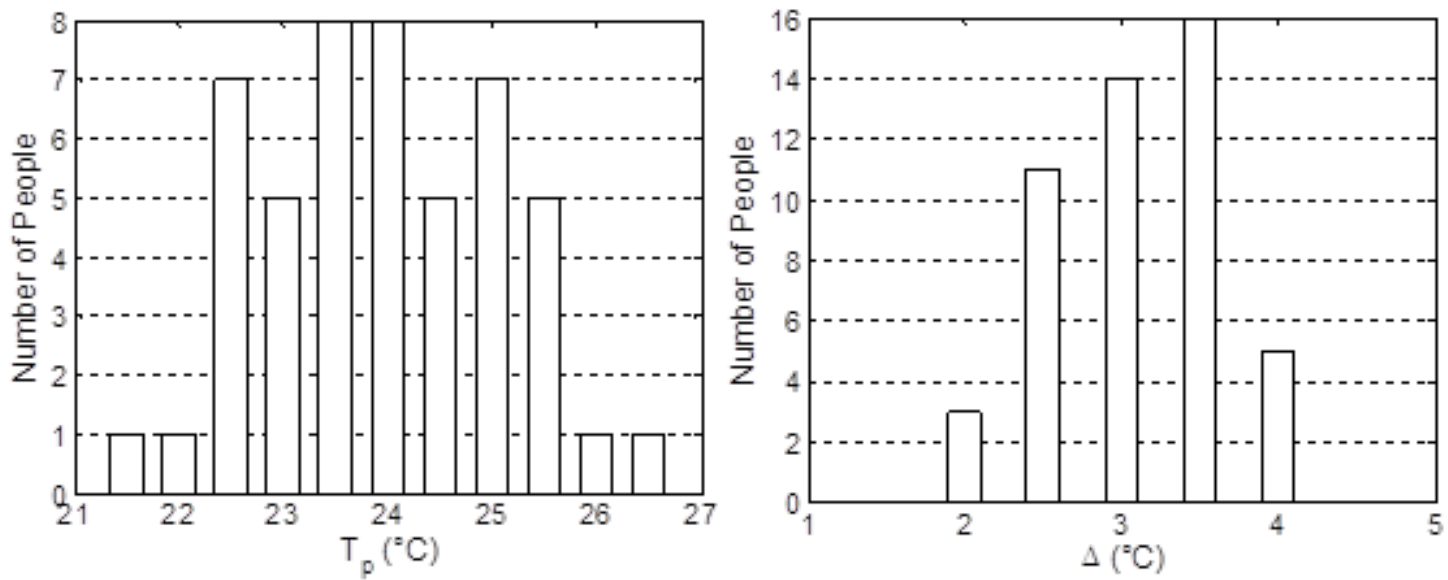

Figure 7 The histograms of $T_{p}$ and $\Delta$ of an example population

The DID level of every occupant at a given temperature point can be found by looking at the DID curve of every individual, which is illustrated in figure 3 , at that temperature point. When this population is assigned to a building whose thermostats are adjusted to $21^{\circ} \mathrm{C}$, the following histogram of the DID levels of the 49 individual occupants is obtained in figure 8.

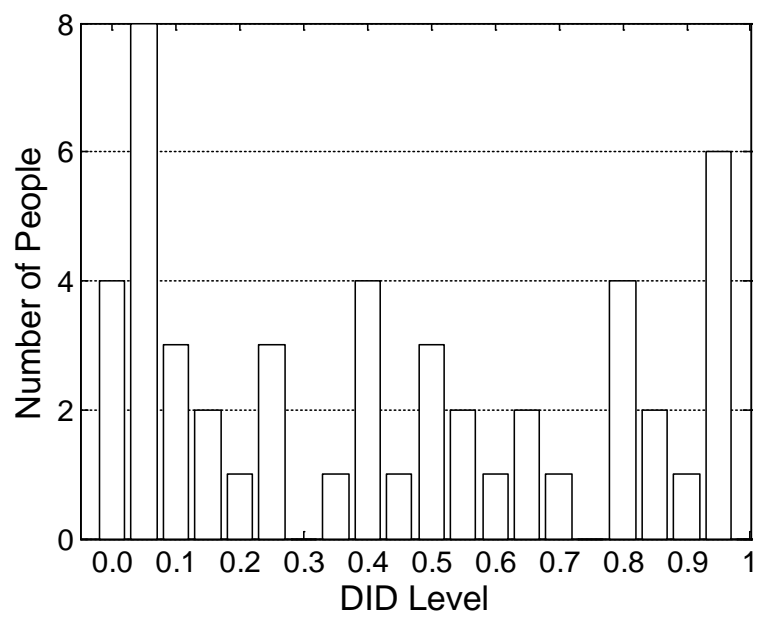

Figure 8 The histogram of DID levels of the occupants in the example population

According to the ASHRAE standard for the thermal comfort of human occupancy, at least $80 \%$ of the population has to be satisfied with the thermal environment making less than $20 \%$ of the population dissatisfied. The overall PPD value of this example population can be obtained through equation 6 . A $\mathrm{PPD}_{\text {gen }}$ of $46 \%$ is obtained when the surrounding temperature of every individual is $21^{\circ} \mathrm{C}$ for this particular population. Because the thermostats in the building were not adjusted according to the ASHRAE standard, the initial thermostat settings do not satisfy its 20\% PPD requirement.

\section{Conclusion}

We have presented a new measure to individual's thermal comfort by introducing the degree of individual dissatisfaction in a fuzzy concept allowing us to scale an individual dissatisfaction level from 
0 (totally satisfied) to 1 (totally dissatisfied) for a given surrounding temperature. We were able to generate a close match to standard population curve from the aggregated curves of our generated thermal comfort preferences of different individuals.

By utilizing our thermal comfort concept introduced in this paper, the simulation of indoor environmental control systems taking into account thermal comfort of individuals and populations will be much more practical than setting up an experimental environment with a large number of people.

Before our concept to thermal comfort, individuals have been considered either satisfied, which is 0 in our model, or dissatisfied, which is 1 in our model, with their surrounding thermal environment. In an optimization problem of indoor environmental control systems, satisfaction of individual occupants can be utilized as constraints or an objective function. This binary or crisp satisfaction criterion makes the constraints or an objective function of such an optimization problem discontinuous. Therefore, the solution may not be obtainable when the constraints or the objective function are not continuous or differentiable. The presented DID measure of individual occupants in a building takes into account satisfaction criteria as a fuzzy or continuous concept described in equation 4, and that makes such an optimization problems of indoor environmental control systems solvable in which thermal comfort preferences of individuals are utilized as constraints or an objective function.In this section you can find information on how to format tables and figures in your paper.

\section{References}

[1] United States Department of Energy and United States Environmental Protection Agency Sustainable Building Technical Manual, 1996.

[2] P. O. Fanger, Thermal Comfort: Analysis and Applications in Environmental Engineering, New York, McGraw-Hill, 1972.

[3] H. Awbi, Ventilation of Buildings. London, Spon Press, 2003.

[4] F.C. Houghton and C. P. Yaglou, Determining Lines of Equal Comfort, ASHVE Trans., vol. 28, pp. 163-176, 1923.

[5] C. - E. A. Winslow, L. P. Herrington, L. P. Gagge, and A. P. Gagge, Relation Between Atmospheric Conditions, Physiological Reactions and Sensations of Pleasantness, Am. J. Hyg., vol. 26, pp. $103-115,1937$.

[6] C. P. Yaglou, A Method for Improving the Effective Temperature Index, ASHVE Trans., vol. 53, pp. 307 - 326, 1947.

[7] A. P. Gagge, J. A. J. Stolwijk, and Y. Nishi, An Effective Temperature Scale Based on a Simple Model of Human Physiological Regulatory Response, ASHRAE Trans., vol. 77, pp. 01: 247 01:262,1971.

[8] P. O. Fanger, Calculation of Thermal Comfort: Introduction of a Basic Comfort Equation, ASHRAE Trans., vol. 73(2), 1967.

[9] P. E. McNall Jr, J. Jaax, F. H. Rohles, R. G. Nevins, and W. Springer, Thermal Comfort (Thermally Neutral) Conditions for Three Levels of Activity, ASHRAE Trans., vol. 73(1), 1967.

[10] R. G. Nevins, F. H. Rohles, W. Springer, and A. F. Feyerherm, A Temperature - Humidity Chart 
for Thermal Comfort of Seated Persons, ASHRAE Trans., vol. 72, pp. 01:283 - 01:291,1966.

[11] F. H. Rohles, Thermal Sensations of Sedentary Man in Moderate Temperature, Kansas, Report to the Institute for Environmental Research, Kansas State University, 1970.

[12] A. P. Gagge, A. C. Burton, and H. C. Bazett, A Practical System of Units for the Description of the Heat Exchange of Man with His Environment, Science, vol. 94, pp. 428 - 430, 1941.

[13] A. P. Gagge, A. P. Fobelets, and L. G. Berglund, A Standard Predictive Index of Human Response to the Thermal Environment, ASHRAE Trans., vol. 92, pp. 02:709 - 02:731,1986.

[14] ASHRAE Standard 55 - 2004, Thermal Environmental Conditions for Human Occupancy, Atlanta, GA, American Society of Heating, Refrigerating and Air Conditioning Engineers, 2004.

[15] ISO / DIS 7730 : 2003, Ergonomics of Thermal Environment - Analytical Determination and Interpretation of Thermal Comfort Suing Calculation of the PMV and PPD Indices and Local Thermal Comfort Criteria, International Organization for Standardization, 2003.

[16] F. H. Rohles, Temperature or Temperament: A Psychologist Looks at Thermal Comfort, ASHRAE Trans., vol. 86, pp. 01:541 - 01:551,1980. 